\title{
Anthropogenic effects on climate
}

\section{Opinion}

There is speculation that with the development of civilization has changed water circulation between the atmosphere and the earth as a result of anthropogenic impacts. Over millions of years it has stabilized a certain balance. Precipitations in a predetermined area in a given volume, a predetermined sequence. It works automatically regulation that created a certain rhythm and climate comfort. Heating the soil leads to the evaporation and increase cloudiness. Clouds shade the soil and reduce solar radiation - reduced. Evaporation - cloudiness decreases-radiation increases.

Man has destroyed and continues to destroy the flora and fauna: more than $60 \%$ of the land used for arable land, artificial reservoirs, landfills, areas of cities and roads, deforestation. ${ }^{1}$ The area occupied by humanity itself is small, only $4 \%$, but the number of storey's of buildings and structures raises her several times. It is enough to understand that each cup of washed, each square meter of wet cleaning of property and all the rooms, fills the atmosphere vapors, not provided by nature. There are some data that each person consumes 200-300 liters of water per day.

Even more people produces fumes in municipal and industrial processes carried out around the clock and all year round. Numerical data are not available, but rather to imagine what the nature of water consumption is not provided and the rate of their proportion to the growing world population, an increase in productivity in all areas, the release of new products. Making each subject requires water flow. For example, for the manufacture of 1tone of adhesive $400 \mathrm{~m}^{3}$ of water is required. This evaporation is also unnatural; reduce the movement of water through the food chain. Studies of these fumes are not found, but dialectically, we have reduced the functionality or the main purpose of the water. It is known that one hectare of soil contains 20tons underground fowl. ${ }^{2}$ Each unit, which is waiting for the water from precipitation. The rate of evaporation from this fowl is economical enough for its existence and reproduction. Biota accumulates moisture and carefully consumed before the next rainfall. Water that is taken away from nature, separated from their natural functions. With the degraded surface of the water goes into the ground, entering the aquifers, the other evaporates almost instantly with asphalt, dumps, arable land. We conclude that the amount of water vapor is much higher than the artificial and the natural, all raised in the air, lost his sense of natural "schedule" may fall anywhere floods drown it at any time.

Catastrophically rapidly disappearing natural link - the transformation of water into organic matter with its reduction. Mankind evaporates the water day and night, all year round. It appears new water cycle, unnatural origin. Water makes the circuit without performing its natural mission. Everything in our world is interconnected. Every action has its consequences. Elevated amounts of artificial evaporation from the increased intensity fumes create a new law, another cycle of the water cycle. But it is not natural, but man-made cycle. Broken mechanism of natural regulation. According to the decisions of the Paris climate conference in 2015 named the main reason - a greenhouse gas, and chief among them carbon dioxide. However, in the age-old reference materials shown are the
Volume 2 Issue I - 2017

\author{
Halidullin $\mathrm{O}$ \\ Ecology Professor cademician of the Russian Federation LAN, \\ Kazakh National University, Russia
}

Correspondence: Halidullin O, Ecology, Professor cademician of the Russian Federation LAN, Kazakh National University, Russia,Tel 87770550099,Email 7II5215@mail.ru

Received: March 28, 2017| Published: March 3I, 2017

ratio of greenhouse gases in the atmosphere: Water vapor $\mathrm{H}_{2} \mathrm{O}$ 36$72 \%$ Carbondioxide $\mathrm{CO}_{2}-9-26 \%$ Methane $\mathrm{CH}_{44}-9 \%$ Ozone $\mathrm{O}_{3}-3-7 \%$.

Steam more than anything more than double these data and this content increases with new technologies. Humanity is taking some on individual elements "environmental conservation" measures, such as reduction of $\mathrm{CO}_{2}$. However, carbon dioxide is a particular one of the circuit elements in the nature of the substances, its content is negligible compared with the volume of water vapor in the atmosphere. And $\mathrm{CO}_{2}$ does not reduce radiation because it is transparent. It is assumed that the term "greenhouse gas" is not critical in the formation of atmospheric phenomena. The decisive factors influencing them is cloud covering vast sizes, shapes, stability of existence, abundant condensation, the growth rate and discharge. Circulation artificial fumes involve in its process and turn all the other components of the atmosphere, including carbon dioxide. Thus, it defined a new source of human impact on climate - artificial evaporation - new circuit water. From this perspective, the main concept of the "greenhouse gas" is subjected to strong doubt. The primary contributor to climate change steam is 0condensed into droplets and forming an impermeable layer of high cloud volume acting on the penetration of solar radiation.

It is urgent to develop a new global concept, redefining the essence of the entire population of the planet destruction of natural phenomena. To preserve habitats for nashih descendants need to begin now to restore the natural evaporation - the basis of the universe. Can form the basis of a new concept: • urgent development of alternative energy in order to stop the construction of a dam with power flooding huge areas

- Need a total savings of water consumption.. Revise all industrial and municipal processes to transfer water consumption in closed cycles.

- Reconstruction of agriculture, the transition to the drip irrigation, reducing irrigation systems, moldboard plowing.

- Termination of soil clogging landfills and dumps and remediation of existing dumps. Create waste-free technologies.

- Reduce wash everything clean and dry. There are, it is necessary to develop new methods of dry-cleaning of surfaces and objects, such as cars, clean asphalt pavements and roads.

- Outside landscaping of buildings and structures. The walls and roofs of buildings and all structures can be covered with vegetation. For example,. ${ }^{3}$ 
- Gradual transition to underground and underwater construction starting with the development of ore dressing, smelting, and the finished product - all this can be done underground in depleted areas. If it's metal, it is transported to the surface of the finished metal. If it is oil derived fuels only. If uranium is derived electricity.

- All types of production should be located under the ground. And then everything else up to the property. There are many commercial areas and the underground in many major cities. There are real projects underwater and underground cities. For example,. ${ }^{4}$ There are underground greenhouses are grown yearround every green.

- Only a general mobilization in this direction can give the effect of the return of natural evaporation and the natural circulation of water - the basis of the universe. Of course, all this is not done suddenly, immediately. But in a reasonable scale mankind should gradually come to this Gipoteza requires evidence of research. Sources:

\section{Acknowledgements}

None.

\section{Conflict of interest}

The author declares no conflict of interest.

\section{References}

1. http:/geographyofrussia.com/razrushenie-estestvennyx-ekosistem/

2. http://smoldacha.ru/osnovy_prirodnogo_zemledeliya.html

3. http://www.novate.ru/blogs/070116/34482/

4. http://gearmix.ru/archives/2174 